\title{
Pluralidade da representação na América Latina
}

Maria da Glória Gohn*

Resumo: Este texto destaca formas de ações coletivas civis organizadas em movimentos sociais ou redes sociais que participam de programas e projetos sociais institucionalizados na América Latina, com destaque para o caso brasileiro na última década. As questões investigadas são: Quem são os atores sociais que protagonizam essas ações associativas? Que público e demandas representam? Que impactos essas demandas geraram na sociedade e no poder público? Que respostas elas têm obtido? Ao final, desenvolvem-se algumas considerações sobre as manifestações sociais ocorridas em junho de 2013 no Brasil, no contexto dos cenários apresentados ao longo do texto.

Palavras-chave: representação sociopolítica; participação; movimentos sociais; associativismo civil; conselhos e fóruns públicos.

\section{Apresentação}

N a última década, a pauta da agenda social latino-americana tem destacado temas como: inclusão social, democratização, diversidade, diferenças, direitos culturais, identidades de povos originários ou de minorias populacionais, sustentabilidade, empoderamento social etc. Esses temas são frutos de problemas socioeconômicos históricos e entraram na pauta de governantes e nas políticas públicas após serem demandados, debatidos e pressionados por atores da sociedade civil organizada, em ações civis estruturadas em movimentos ou redes de associações civis não governamentais.

Quem são os atores sociais que protagonizam essas ações coletivas? Que público e demandas representam? São movimentos ou organizações civis os núcleos impulsionadores dessas ações? Quais são as principais organizações sem fins lucrativos da sociedade civil voltadas para ações coletivas atuando em função de problemas sociais, econômicos, culturais e ambientais públicos? Como elas atuam para a superação das desigualdades sociais e regionais? Que impactos essas demandas geraram na sociedade e no poder público? Que respostas elas têm obtido? Essas são as questões inspiradoras deste texto.

Inicia-se com a apresentação de um painel geral de formas associativas civis contemporâneas organizadas em movimentos na América Latina objetivando contextualizar e analisar as transformações recentes que vêm ocorrendo neste cenário. Em seguida, o texto destaca, para análise, movimentos sociais e formas de associativismo civil

\author{
* Professora titular \\ da Faculdade \\ de Educação da \\ Unicamp, doutora \\ em ciência política \\ pela USP e pós- \\ doutora pela New \\ School/New York \\ em sociologia. \\ Pesquisadora \\ do CNPq, vice- \\ presidente do $\mathrm{RC}$ \\ 47 da Associação \\ Internacional de \\ Sociologia, é autora \\ de 18 livros, entre \\ os quais Sociologia \\ dos movimentos \\ sociais (2. ed., \\ São Paulo: Cortez, \\ 2014) e Teorias dos \\ movimentos sociais \\ (10. ed., São Paulo: \\ Loyola, 2012). \\ <mgohn@uol.com. \\ br>.
}


específicos no Brasil. Ao final, faz-se uma síntese dos movimentos de protestos que ganharam a denominação de "manifestações de ruas em junho de 2013 no Brasil", apontando questões teórico-metodológicas implícitas (Gohn, 2014).

\section{O novo cenário dos movimentos latino-americanos no século XXI}

Na primeira década deste século, em alguns países da América Latina, houve uma radicalização do processo democrático (Svampa, 2008) e o ressurgimento de lutas sociais já ocorridas décadas atrás, a exemplo de movimentos étnicos - especialmente dos indígenas na Bolívia e no Equador -, associados ou não a movimentos nacionalistas como o dos bolivarianos (Venezuela). Movimentos que estavam na sombra e eram tratados como insurgentes emergem com força organizatória, como os piqueteiros na Argentina, os cocaleiros na Bolívia e no Peru, os zapatistas no México (Boron e Lechini, 2006). Outros se articularam às redes de movimentos sociais globais, como o Movimento dos Trabalhadores Rurais Sem Terra (MST) no Brasil e a Via Campesina. Convenções globais têm articulado esses movimentos em grandes eventos, como o Fórum Social Mundial (Seoane e Taddei, 2001; Santos, 2006; 2009) e a Cúpula Mundial dos Povos Rio/2012. O primeiro, apesar de se apresentar como transnacional, constitui uma das novidades específicas do associativismo latino-americano deste século e teve a maioria de suas edições em Porto Alegre/Brasil.

Entre os movimentos de demandas identitárias na América Latina destaca-se o movimento de povos indígenas, especialmente nos países de língua espanhola. Sabe-se que a luta dos povos indígenas de resistência à colonização europeu-branca é secular. Na atualidade, o elemento novo é a forma e o caráter que essas lutas têm assumido - não apenas de resistência, mas também de luta por direitos: reconhecimento de suas culturas e da própria existência, redistribuição de terras em territórios de seus ancestrais, escolarização na própria língua, defesa do meio ambiente etc. Deve-se assinalar também que inúmeros territórios indígenas passaram a ser, em vários países, fonte de cobiça devido aos minerais e outras riquezas de seu subsolo, assim como seus cursos d'água, ou meramente por estarem localizados em rotas onde se planejam gasodutos e outras intervenções macroeconômicas, acirrando as tensões sociais, a exemplo dos conflitos na Bolívia (pela água em Cochabamba, em 2000; na questão do gás, nas negociações com o Brasil, entre 2003 e 2005; e os conflitos na construção de uma rodovia de $300 \mathrm{~km}$ para dinamizar o comércio entre as terras baixas da Amazônia boliviana e os vales andinos). Registram-se também conflitos no Peru (bloqueio dos Aymará em Lima, 2000-2001). São todos conflitos complexos envolvendo interesses econômicos, políticos e culturais.

No Brasil, os conflitos de terras em zonas indígenas, na Floresta Amazônica, se acirraram depois do novo boom e furor na plantação de cana-de-açúcar para a produção do álcool, reputado como nova alternativa energética para o consumo. 
Nesta breve lista de movimentos sociais hoje na América Latina, registre-se o movimento dos estudantes, especialmente no Chile, com a Revolta dos Pinguins (Zibas, 2008) e as marchas de 2011-2012 por reformas na educação. Em Santiago do Chile, em 2011, 400 mil pessoas saíram às ruas para pedir educação pública de qualidade gratuita para todos. O movimento dos estudantes no Chile tem sido considerado um avanço na luta latino-americana, porque suas pautas não se limitam às melhorias em suas escolas, demandam reformas na educação e denunciam os efeitos setoriais das políticas neoliberais dos últimos anos. Aliás, não são apenas os estudantes que se têm mobilizado naquele país pela educação.

A área da educação - especialmente a da educação básica - tem sido a fonte de protestos de grandes dimensões já faz algum tempo na América Latina, a exemplo do México, em 2006, na região de Oaxaca. Devemos destacar também que a área da educação, devido ao potencial dos processos educativos e pedagógicos para o desenvolvimento de formas de sociabilidade e constituição e ampliação de uma cultura política, passou a ser uma área estratégica também para os movimentos populares, a exemplo do MST no Brasil, que desenvolve pedagogias próprias, cartilhas e materiais pedagógicos, tem escolas próprias e busca a formação dos professores que atuam em suas escolas, em projetos desenvolvidos em parceria com universidades públicas brasileiras.

Observa-se, ainda na primeira década no século XXI, a retomada do movimento popular urbano de bairros, notadamente no México e na Argentina. Essa grande mobilização tem eclodido na cena pública como agente de novos conflitos e renovação das lutas sociais coletivas. Em alguns casos, elegeram suas lideranças para cargos supremos na nação, a exemplo da Bolívia.

Os problemas gerados pela globalização da economia provocaram consequências no cenário da organização da população em geral. O estímulo que as políticas econômicas deram ao setor informal da economia, nos anos de 1990, levou ao surgimento de extensas redes produtivas comunitárias expandindo o chamado Terceiro Setor, onde há grande presença de ONGs (Di Marco e Palomino, 2004). Elas desenvolvem projetos com as populações demandatárias de bens e serviços, organizadas em redes associativas, operando por meio de projetos que necessitam de ser financiados e qualificados para ter continuidade. Ou seja, a ação coletiva presente na maioria dos movimentos sociais latino-americanos, de pressão e reivindicação nos anos de 1980, diversifica-se a partir dos anos 1990 e durante a primeira década de 2000 passando a incluir também ações civis voltadas para a obtenção de resultados, em projetos de parceria envolvendo diferentes setores, públicos e privados.

Acrescente-se ao cenário a rede de participação gerada pelos conselhos, câmaras e fóruns, implementada pelo poder público via políticas sociais, algumas para atender 
novas exigências constitucionais. Com isso, a participação institucionalizada, regulada por normas e regras do setor público estatal passou a ocupar grande espaço no cenário associativo antes dominado pelos movimentos sociais da sociedade civil. De acordo com Tapia (2009), para entender a construção e a dinâmica do sujeito nas lutas e nos movimentos sociais da América Latina, temos de compreender as novas políticas institucionalizadas da região.

Resulta que, na primeira década do século XXI, o cenário do associativismo latino-americano se altera aos poucos, novos tipos de ações coletivas e de movimentos sociais emergem no final da década (Mirza, 2006; Abers e Von Bulow, 2010). Há novidades nas demandas, nas identidades, nos repertórios e no perfil dos participantes. Proliferam movimentos multi e pluriclassistas. Surgem movimentos transnacionais, que ultrapassam fronteiras do Estado-nação e vão além do movimento alter ou antiglobalização, a exemplo da Coordinadora Latinomericana de Organizaciones del Campo (Cloc). As marchas e as ocupações tornaram-se o modelo básico de protesto, modelo esse que será retomado na segunda década do século XXI, aliado a outras inovações na forma do protesto, que é o uso das novas tecnologias, especialmente as redes digitais e redes sociais. São movimentos inspirados nos Indignados europeus, ou no Occupy Wall Street (Della Porta, 2007; Di Cintio, 2010). Formados predominantemente por jovens, a maioria sem trajetória anterior de participação política em partidos e sindicatos, eles estão reformulando a pauta das demandas identitárias, a exemplo da luta contra discriminações de gênero, com a Marcha das vadias, movimento transnacional. Também estão retomando as demandas grupais focadas em problemas da vida cotidiana - emprego, finanças/salário, dívidas, serviços sociais como transporte, educação e saúde, terra para viver e plantar (demanda já secular, agora em confronto com o agronegócio), entre outras.

\section{Novas mudanças no associativismo civil na virada da primeira década do século XXI}

O fato de destaque na atualidade é que a crise financeira global de 2008 deu suporte para o nascimento de novos movimentos sociais, tanto no mundo ocidental (Occupy Wall Street, em Nova York; Indignados, na Europa), como no Oriente (Primavera Árabe e outros) (Ali et alii, 2012; Castells, 2013), e na Turquia (defesa do Parque Gezi e da Praça Taksim, em Istambul). Passaram da antiglobalização (ou alterglobalização) para a negação da globalização e de seus efeitos sobre a economia e o social. Os movimentos de indignados contra a globalização estão alcançando a escala global. A indignação - categoria que pode ser analisada em vários planos, especialmente o moral -, pautada nos valores, na ética e na justiça social, tem ganhado centralidade nas ações coletivas. Apesar das diferenças históricas entre os movimentos acima citados e os que ocorrem na América Latina - a serem tratados adiante-, os novíssimos movimentos dos indignados 
influenciaram a agenda e a pauta das lutas sociais latino-americanas na década iniciada em 2010, dada a conectividade dos grupos de ativistas transnacionais nas redes sociais.

A forma de comunicação predominante on line utiliza-se de redes sociais como Facebook, YouTube, Orkut e Linkedln, acessadas principalmente por aparelhos móveis, como ferramentas do ciberativismo, que se incorporam ao perfil do ativista e tornam-se o meio principal para articular as ações coletivas (Castells, 2013). Por isso, as análises dessas ações têm de incorporar essa importante alteração que interfere nas relações que se estabelecem e estruturam os movimentos. A transnacionalização advém dessas alterações, ainda que os ativistas estejam reivindicando questões locais. Alguns são movimentos virtuais, sem sede ou grupo organizador de grande visibilidade. O registro instantâneo de ações transforma-se em arma de luta, o que gera outras ações como resposta. A preocupação com as redes sociais e digitais leva a abordagens que as tomam como processos em andamento e buscam construir metodologias para captar as conexões entre o global e o local, suas interações cognitivas a partir de rastros dados pela comunicação e mídias digitais (Diani e Macadam, 2003). O trabalho do pesquisador é cognitivo e político, uma vez que ele deve realizar um rastreamento para elaborar a cartografia de processos sociais "se fazendo" e não já dados, prontos ou acabados. Recomenda-se retraçar os percursos captando-se as inquietações, os conflitos e as controvérsias, porque as redes são polissêmicas, diversas e não unívocas. Os estudos destacam como os atores tecem seus percursos na rede, mas o pesquisador continua essa tessitura ao elaborar suas cartografias. Algumas das questões que se colocam são: Quais espaços cognitivos e políticos os ativistas utilizam? Que saberes constroem? Como se autorrepresentam? Qual a cartografia de seus embates coletivos? (Latour, 2005).

Com o este cenário dos movimentos sociais, novos aportes teóricos são desenvolvidos ou reelaborados, especialmente na América Latina. Novas ênfases ocorrem nas teorias já existentes. Teorias que tinham hegemonia na América do Norte difundem-se na realidade latino-americana e passam a ser eixos referenciais importantes, a exemplo da Teoria da Mobilização Política, com destaque para as oportunidades políticas e os litígios políticos de Tilly e Tarrow (2007) e outros. O marxismo ressurge renovado (Linera, 2009; Harvey, 2011; Zizek, 2012; Quijano, 2004), ao lado de outros aportes teóricos como o socialismo libertário (De Cintio, 2010), e o novo humanismo holístico (Hessel, 2011; Dussel, 2002; Spivak, 2008; Walsh, 2010). Ocorre, pois, uma repolitização dos movimentos sociais pós-2008 sob novos paradigmas inspiradores das ações coletivas, muitos deles construídos a partir de ideias e utopias já bem antigas, como o socialismo libertário, o anarquismo, o autonomismo e outros, porém totalmente renovados sob a égide da sociedade contemporânea com seus problemas, desafios e recursos comunicacionais e tecnológicos. Em síntese, as utopias, que, desde a queda do Muro de Berlim, há mais de 20 anos, eram criticadas e então consideradas como mortas, porque foram erroneamente identificadas como totalitarismo, ressurgem 
nesta nova década, lastreadas em referenciais libertários, para projetar o futuro, no qual não se sabe bem o que se quer, mas se sabe muito bem o que não se quer. Saliba (2004) chama esse processo de distopia. Retomaremos esse aspecto ao final, ao tratarmos das manifestações de junho de 2013 no Brasil.

\section{O associativismo no Brasil contemporâneo}

Neste novo século, o Brasil está entre os países que capitalizaram a crise com sua inserção em nichos do mercado internacional, promovendo fortes políticas de proteção social, com programas que promovem a interação entre movimentos sociais, sindicatos, associações e ações coletivas, e órgãos governamentais, tudo aliado a políticas de recuperação do salário dos trabalhadores. Essa interação se faz via políticas institucionalizadas, e pode ser observada em grandes conferências nacionais e nas políticas focalizadas para segmentos sociais, como os afrodescendentes ou as mulheres, ou políticas sobre temáticas sociais, como a alimentação. Todas elas denominam-se políticas de inclusão ou de proteção social. O elemento comum é a territorialização/espacialização das ações coletivas e a tematização dos conflitos sociopolíticos e culturais. Há um grande número de redes civis de atuação direta junto à população por meio de ONGs, associações comunitárias, sociedades de amigos de bairros, entidades assistenciais e filantrópicas, laboratórios de projetos sociais de extensão universitários etc. Trata-se de um setor que não é marginal ao modelo econômico vigente. O trabalho e a organização cotidiana desse setor contribuem para alimentar cadeias de produção. Basta citar a área de reciclagem de papel, papelão e outros materiais, na qual, sem o trabalho de cooperativas, de ONGs e entidades assistenciais, não se viabilizariam a coleta e a separação dos materiais.

Cumpre lembrar que, após 1988, os municípios brasileiros passaram por alterações na administração pública, com a descentralização e a inserção de formas de participação da sociedade civil na reforma política do Estado. Os territórios das cidades e microrregiões adquiriram força institucional para o desenvolvimento de projetos sustentáveis e estabeleceram-se novas relações entre o Estado, a população e o mercado.

Disso tudo resulta que a sociedade civil brasileira organizada contemporânea não é homogênea, nem composta por atores com o mesmo entendimento dos problemas sociais, políticos e culturais da sociedade. A sociedade civil apresenta um quadro bastante diversificado, no qual se destacam as redes associativas e de mobilização. Podemos aglutinar esse leque diferenciado de atores coletivos em quatro sujeitos sociopolíticos, a saber:

I. Movimentos sociais - considerados como categorias empíricas, podendo ser localizados territorialmente, ou como categoria conceitual, 
forma de estruturação de relações sociais, conforme definiu Melucci (1994);

II. Entidades sem fins lucrativos - subdivididas em ONGs independentes, entidades assistenciais e entidades do mundo empresarial articuladas pelo chamado Terceiro Setor;

III. Fóruns, plenárias e articulações nacionais e transnacionais;

IV. Conselhos gestores de projetos, programas ou políticas sociais; conferências nacionais; consórcios inter-regionais; fóruns de promotorias públicas, observatórios temáticos de acompanhamento, diagnóstico e banco de dados de políticas sociais públicas etc.

\section{Movimentos sociais no Brasil no século XXI ${ }^{1}$}

Após o grande debate sobre a crise dos movimentos sociais nos anos 1990 no Brasil, ao final da primeira década deste século foi publicada uma série de artigos e balanços temáticos demonstrando que eles retornaram à cena pública e à pauta de interesse dos pesquisadores. Esses estudos diagnosticaram que antigos movimentos sociais -a exemplo da luta pela moradia ou da luta pela terra - passaram a conviver com novos movimentos, organizados segundo múltiplas identidades - negro, mulher, idoso, jovem/adolescente etc. Lutas sociais por reconhecimento convivendo com lutas pela redistribuição e pelo acesso a bens e serviços. Os antigos movimentos sociais das décadas de 1970 e de 1980 não desapareceram, tornaram-se mais fragmentados, menos articulados com sindicatos, pastorais ou partidos, alguns mais próximos de projetos e programas sociais desenvolvidos no plano institucional; outros de costas para o Estado, ou para os políticos e os partidos.

Acrescente-se à lista das mobilizações no Brasil neste novo século a participação das mulheres em movimentos e organizações no campo da organização alimentar, cooperativas solidárias etc.; e o movimento dos afrodescendentes, que cresceu bastante no novo século com o apoio do poder público em questões como a dos quilombolas (terras de ex-escravos), cotas para acesso às universidades públicas e privadas, a estas últimas por meio do Programa Universidade para Todos (Prouni).

Os movimentos sociais no setor agrário também se proliferaram no novo século, mas com perfis e atuações variadas e diversificadas. Estão em cena não apenas os Sem Terra, mas também pequenos agricultores e assentados pelas políticas públicas, e suas lutas para implementarem a produção no campo. E ocorreram momentos históricos importantes dos movimentos sociais rurais em relação à educação a partir do Movi-

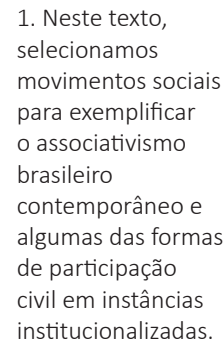


mento Nacional por Educação do Campo (Mned) e as atividades do Encontro Nacional de Educadoras e Educadores da Reforma Agrária (Enera). Ao longo da primeira década deste século, os movimentos rurais passaram a participar de grupo de trabalho permanente junto ao Ministério da Educação (MEC), que incorporou a função de articulação das ações do governo com as demandas dos movimentos. Nesse sentido, em 2004 ocorreu a II Conferência Nacional por uma Educação Básica do Campo, ampliando mais o leque das articulações. Outra novidade importante neste novo século foi a criação de cursos de graduação desenvolvidos em universidades públicas para formar profissionais para trabalharem no campo. Destacam-se os cursos de pedagogia para formar professores que irão atuar nos assentamentos, especialmente em universidades no estado do Paraná (Unioeste, por exemplo). Alguns destes cursos têm como alunos integrantes do próprio movimento, especialmente do MST, com uma estrutura e grade curricular diferenciada.

\section{A participação em instâncias institucionalizadas}

O novo século apresentou-nos mudanças nas políticas sociais, desconcentração de várias atividades estatais na área social, aplicação das novas legislações no âmbito federal com a criação de organizações sociais (OSs), organizações da sociedade civil de interesse público (Oscip's) e programas em parceria público-privado (PPP), entre outras alterações de ordem institucional. Ocorreram a desativação da atuação direta do Estado na prestação de alguns serviços sociais e a transferência da operacionalização desses serviços para o setor privado sem fins lucrativos. Isso tudo contribuiu para a reconfiguração do cenário do associativismo civil brasileiro, gerando a criação de espaços de interlocução entre o Estado e a sociedade civil. Novas redes de participação institucionalizadas foram criadas com conselhos, câmaras, fóruns e assembleias nacionais, implementadas pelo poder público via políticas sociais para atender novas exigências constitucionais. Redes civis focadas em projetos socioculturais, entidades geradoras de renda via economia solidária, parcerias público-privado em projetos socioeducativos nas escolas etc. passaram a dominar a cena do associativismo no novo século, fortalecendo o campo de uma cultura comunitária local, com ativistas focados no cumprimento de metas dos projetos sociais envolvidos, e não mais militantes de causas e organizações com vínculos político-partidários e sindicais.

Novos e antigos atores sociais fixaram suas metas na conquista de espaços na sociedade política, especialmente nas parcerias que se abrem entre governo e sociedade civil organizada, via políticas públicas. Houve, portanto, uma ampliação do leque de atores sociais, assim como uma ampliação do campo da sociedade civil. Disso resultou um descentramento dos sujeitos históricos em ação, antes focados nas classes populares e nos movimentos populares. Surgem novas facetas à cidadania tais como o exercício da civilidade e a responsabilidade social do cidadão como um todo. Ou seja, não ape- 
nas foram destacados os direitos, que são a alavanca básica do conceito de cidadania, mas também foi introduzida a questão dos deveres, da responsabilização nas arenas públicas, e essa responsabilização abriu caminhos para a participação de diferentes e novos atores sociais nas políticas de parcerias entre o Estado e a sociedade civil. Enfatiza-se agora a responsabilização dos cidadãos, das empresas e dos órgãos governamentais nas novas políticas públicas; criam-se espaços para a participação nessas políticas mediante parcerias, ou nos espaços criados institucionalmente, como os conselhos gestores e os fóruns sociais públicos.

No novo cenário de ampliação dos processos de inclusão social, reconhecimento de diferenças socioculturais e institucionalização de procedimentos no atendimento de demandas, novos direitos são criados e outros são reformulados. Scherer-Warren fala em geração de novos direitos no Brasil, o que requer algumas premissas, a saber:

As maiores ou menores possibilidades de geração de novos direitos em uma sociedade estarão relacionadas à existência ou não de um Estado democrático de direito que permita manifestar seus conflitos sociais e equacionar demandas materiais e simbólicas através de movimentos sociais, grupos de pressão institucional e/ou representantes da própria esfera estatal (Scherer-Warren, 2012: 216).

O Conselho Nacional de Segurança Alimentar (Consea) pode ser citado como exemplo do novo cenário. O Consea passou a incorporar em sua estrutura representantes da sociedade civil e criou inúmeros programas e políticas, tais como Marco Estratégico Mundial para a Segurança Alimentar e Nutricional, uma política do governo brasileiro de apoio à agricultura familiar, com ações estratégicas imediatas e ações estruturantes de longo prazo. Há projetos específicos para incorporar as mulheres no acesso à terra e aos meios produtivos. Criaram-se estruturas como o Fórum Nacional de Segurança Alimentar e Nutricional dos Povos de Terreiro (Fonsanpote) voltados às populações afrodescendentes. ${ }^{2}$ Populações indígenas também têm sido contempladas com os programas oficiais.

2. Cf. <http://www4. planalto.gov.br/ consea>.

Observa-se, nos exemplos acima enumerados, uma ampliação das formas de gestão deliberativas, criando-se inúmeras inovações no campo da participação popular democrática, como a participação via eletrônica; assim como se construiu e/ou redesenhou o formato de várias políticas sociais com a generalização do uso de grandes conferências nacionais copatrocinadas por órgãos públicos. A institucionalização de canais e práticas da sociedade civil, em sua relação com a sociedade política, produziu também novos movimentos sociais, a exemplo de movimentos sociais que atuam em questões relativas à democratização do Estado ou das políticas públicas, como o Movimento de Combate à Corrupção Eleitoral (MCCE). 


\section{A Retomada dos movimentos de rua no Brasil: as manifestações de junho de 2013}

No início da segunda década deste século, surgem novidades que atingem seu clímax em junho de 2013. Algumas dessas novidades foram geradas pelos movimentos antiglobalização e alterglobalização da década anterior, quando o escopo das lutas ampliou-se para dimensões territoriais além do Estado-nação, focalizando críticas aos ajustes estruturais provocados pelas políticas macroeconômicas (que geram diminuição da proteção ambiental, esvaziamento de direitos trabalhistas etc.).

A novidade maior foi a retomada das mobilizações, as manifestações e os protestos nas ruas e praças públicas. Passa a haver uma pluralidade de sujeitos e de reivindicações na esfera pública. O foco das demandas converge para temas mais localizados, nacionais, destacando-se a ética e a luta contra a corrupção, assim como protestos que focalizam os serviços públicos, com destaque para os transportes e a questão da mobilidade urbana, a exemplo do Movimento Passe Livre (MPL), precursor da jornada de manifestações de junho de 2013. Enquanto os altermundialistas organizavam seus protestos diante das grandes reuniões de cúpula de entidades e governos capitalistas, as manifestações na nova década reúnem indignados contra as políticas públicas específicas de nações, Estados e capitais.

Em junho de 2013, ocorreu, em 12 capitais e várias cidades de médio porte do país, uma onda de manifestações populares em ruas, praças e avenidas com similares na história do país apenas em três momentos: em 1992, no impeachment do ex-presidente Fernando Collor de Mello; em 1984, com o movimento Diretas-Já, na luta pelo retorno à democracia, durante o regime militar; e nos anos de 1960, nas greves pré-golpe militar de 1964 e nas passeatas estudantis de 1968. O povo desceu às ruas aderindo a um tipo novo de movimento social. Estima-se que mais de um milhão de pessoas participaram desses últimos atos públicos no país.

É importante registrar que há elos entre as duas formas: movimento antiglobalização da primeira década deste século e manifestações nas ruas em 2013. Os ativistas da alterglobalização criaram, ainda ao final do século XX (1998), durante a I Conferência Mundial dos Povos, a Ação Global dos Povos (AGP), que, por sua vez, criou, como braço de comunicação, o Centro de Mídia Independente (CMI) e depois a Indymedia. A AGP incentivou e organizou inúmeros atos de protestos durante as reuniões de cúpula de líderes mundiais, destacando-se as de Seattle, em 1999, e de Gênova, em 2001. Essas manifestações - que refluíram no plano internacional após o atentado do World Trade Center, de Nova York, quando se acirrou o combate às manifestações sob o argumento de combate ao terrorismo - foram a escola de aprendizagem de muitos ativistas das manifestações no início da nova década em várias partes do mundo, 
incluindo as do Brasil. Um dos movimentos que constituíram o MPL foi o Centro de Mídia Independente (CMI) (Ortellado, 2012).

As manifestações de junho foram desencadeadas em São Paulo por coletivos organizados com o predomínio do MPL, a partir de uma demanda pontual - contra o aumento da tarifa dos transportes coletivos. O MPL foi oficialmente criado em 2005, em Porto Alegre, durante o Fórum Social Mundial (FSM), mas tem suas origens nas manifestações que ocorreram em Salvador, em 2003 (Revolta do Buzu) e em Florianópolis em 2004 (Revolta da Catraca), bem como no ativismo do já citado CMI. O próprio MPL autodefine-se como

movimento horizontal, autônomo, independente e apartidário, mas não antipartidário. A independência do MPL se faz não somente em relação a partidos, mas também a ONGs, instituições religiosas, fi-

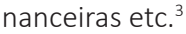

O movimento tem como demanda central a tarifa zero para o transporte coletivo. Segundo Peschanski, a proposta do MPL contém

valores desejáveis a uma alternativa social ao capitalismo: sustentabilidade, solidariedade, eficiência, democracia e comunidade (Peschanski, 2013: 60).

Os protestos de junho de 2013 em São Paulo espalharam-se rapidamente para o Rio de Janeiro, Porto Alegre, Belo Horizonte, Brasília e outras grandes cidades do país e, à medida que crescia o número de pessoas nos protestos de rua, as mais diversas pautas a expressarem as insatisfações da população vieram à tona.

Os manifestantes dirigem suas reivindicações a personagens específicos da cena público-política de cada região do país. Por esta razão, os movimentos brasileiros diferenciam-se dos Indignados da Europa, especialmente Espanha, Portugal e Grécia, países em profunda crise econômica causada pelas políticas neoliberais de ajustes fiscais, controle e monitoramento exercido pelo Fundo Monetário Internacional (FMI), Banco Central Europeu, acirrando a onda de desemprego, com retirada de direitos sociais, corte de salários, dispensa de funcionários públicos etc. Os Indignados brasileiros diferem mais ainda dos movimentos da Primavera Árabe devido à frágil democracia e forte controle social que predominam na maioria daqueles países e as relações entre política e religião via o islamismo. Finalmente os Indignados nacionais diferem do Occupy Wall Street não só porque adotaram formas diferentes de ação, mas porque tiveram, no início, uma pauta específica: contra o aumento da tarifa do transporte público e pela tarifa zero. Eles não ocuparam um território específico, optando por passeatas; nem realizaram bloqueios - tática que passou a ser utilizada depois, em atos que deram sequência às

3. Cf. $<w w w$ saopaulo.mpl.org br>. 
manifestações de junho, em movimentos de caminhoneiros, motoboys, e no Dia Nacional de Luta (11 de julho de 2013), organizado por nove centrais sindicais, pelo MST, pela UNE, movimentos populares de moradia etc. reunindo mais de 100 mil pessoas no país.

Os coletivos que participaram das manifestações em junho de 2013 inspiram-se em variadas fontes, segundo o grupo de pertencimento de cada um. Ao rejeitarem lideranças verticalizadas, centralizadoras, não houve hegemonia de apenas uma ideologia, ou utopia. A política dos manifestantes foi de outra natureza, feita por diversas alianças momentâneas e circunstanciais, nem sempre tão consensuais, a partir das práticas de experiência do momento, continuamente redefinidas, evidenciando a crise no sistema de representação, pois não há fidelidade aos atores políticos constituídos formalmente na arena nacional.

Após junho de 2013, uma tendência de ação coletiva passou a ter destaque nos atos de protestos e manifestações nas ruas - os Black Blocs. Trata-se de tendência com formas de ação surgidas na Europa nas últimas décadas do século passado, com uma estética específica: vestem-se de preto e cobrem os rostos por isso são nominados como "mascarados". Frequentemente usam a violência como forma de ação, designando estas ações como violência simbólica. Há um grande debate sobre o que é e quem são os Black Blocs. Uma tática ou um movimento? Para nós, é um movimento com características singulares: ideologia dos autonomistas/anarquistas reformulada para o contexto da era da globalização, com uso intenso das novas tecnologias na convocação e organização dos atos. São movimentos transnacionais articulados por redes sociais, com ideologias autonomistas de várias fontes e referenciais reformatados, com atuação em contextos e problemas locais.

Destacamos, ainda neste texto, que os manifestantes de 2013, em suas variadas matizes de práticas, ideologias e pertencimentos, não são antiutópicos. Análises que destacam o fim das utopias, ou sua crise e negação - já registramos acima - são restritas, porque veem um dado modelo de utopia, associando-o a um padrão de sociedade totalitária. Os manifestantes de junho de 2013 defendem formas horizontais e não centralizadoras de organização, negam a presença de partidos nas manifestações, mas não são antipartidários. Ao contrário, desde a década de 2010, estão gritando: outro mundo é possível. Qual mundo? Qual utopia? Talvez devêssemos seguir Riot-Sarcey que, no Dicionário das utopias (2009), afirma ser melhor pensarmos na ausência de uma definição unívoca sobre o tema, mas reencontrar o sentido de uma construção imaginária. Ou seja, retomar Thomas Morus, na origem do termo utopia, em 1516, que a caracterizou como discurso sobre o não existente, lugar que não existe ainda, um não lugar, mas lugar onde se está bem. Ou retomar Munford (2007) que, em 1922, analisou as utopias históricas e as distinguiu entre utopias de escape e de reconstrução. 


\section{Conclusões}

Este artigo destacou inicialmente os movimentos sociais na América Latina nos últimos anos. Ao partir de breve caracterização de seu cenário, buscaram-se exemplos naqueles que procuram aliar a especificidade do processo histórico latino-americano com mudanças e transformações globais. Resistência e autonomia são categorias-chave para entender os movimentos dos povos indígenas, dos camponeses etc. Entretanto, novas formas de movimentos sociais têm sido criadas, bastante diferente dos movimentos tradicionais, a exemplo dos movimentos sociais de luta pelo reconhecimento do direito às diferenças (sexuais, culturais, necessidades especiais etc.). Demandas novas emergem de antigas necessidades, como o passe livre para a mobilidade urbana, renovando a luta dos estudantes na cena pública.

Resulta que, no cenário social do novo milênio, os movimentos sociais voltaram a ter visibilidade e centralidade, como atores que pressionam por processos de mudança social e reinventam as formas de fazer política, especialmente após 2008, com a crise que se abateu sobre a economia mundial. Eles também se transformaram bastante, realizaram deslocamentos em suas identidades e incorporaram outras dimensões do pensar e agir social, alteram seus projetos políticos. Mas como são muitos e heterogêneos, parte deles fragmentou-se, perdeu ou redefiniu sua identidade, suas ideias e seus pontos de vista centrais, alterando o projeto e a cultura política existente; outros se redefiniram segundo as mudanças de atores sociais distintos que entraram em cena; outros ainda aproveitaram brechas e se conectaram com as possibilidades dadas pela globalização, perspectiva econômica (geradora de resistências e protestos) e cultural (geradora de novas sociabilidades, novas interações e aprendizagens baseadas na pedagogia do exemplo - aprender via observação - nos grandes eventos transnacionais, ou via conexão na rede internet). O perfil dos participantes alterou-se - de militante para um ativista. As marchas tornaram-se o modelo básico de protesto. As redes sociais substituíram os "muros de Paris" como divulgadoras das demandas, palavras de ordem e articuladoras das ações em si, lembrando e comparando com 1968.

O desenvolvimento do processo democrático em vários países tem levado ao poder central setores políticos que estiveram na oposição ao regime político no passado, a exemplo do Brasil. Novas políticas públicas foram formuladas a partir de diálogos e parcerias com a sociedade civil organizada, criando-se conselhos, fóruns, ouvidorias, observatórios e grandes conferências nacionais públicas.

No plano da pesquisa, é necessário desenvolver indicadores socioculturais e sociopolíticos que possam analisar e avaliar, atuações e políticas sociais dos novos sujeitos contemporâneos que se mobilizam. Os indicadores, os critérios e as categorias utilizados são herança e herdeiros, na maioria das vezes, de uma ciência social já superada, 
que não mais responde às necessidades da atualidade. São indicadores econômicos, quantitativos, criados antes do desenvolvimento das novas tecnologias - que estão revolucionando o mundo das comunicações, das relações sociais e as ações coletivas dos movimentos.

A nova etapa das lutas sociais faz-se aliando as inovações tecnológicas e o retorno das teorias do século XIX, totalmente revisadas (Gohn, 2014a). De um lado, os neomarxistas; de outro, o socialismo libertário, neoanarquistas, e o humanismo holístico, em certos segmentos dos povos indígenas da realidade latino-americana como a teoria do "bien vivir" e a descolonização, especialmente "das mentes". No plano das análises, não se trata mais de contrapor os novos movimentos sociais - nucleados em torno de questões identitárias, tais como sexo, etnia, raça, faixa etária etc. - aos "velhos" movimentos dos trabalhadores - como Claus Offe e outros fizeram na década de 1980, por exemplo. Não se trata, portanto, de contrapor tipos de movimentos ou ações coletivas, ou paradigmas teóricos interpretativos como mais ou menos adequados, até porque, todos eles continuam a coexistir com os novos. Trata-se de reconhecer a diversidade de movimentos e ações civis coletivas, suas articulações e os marcos interpretativos que lhes atribuem sentido e significado novos, objeto da investigação de uma sociologia dos movimentos sociais, que certamente vai além de uma simples cartografia dos movimentos sociais existentes, mesmo se se deve considerá-la como ponto de partida.

Reafirmamos: o cenário das mobilizações alterou-se nesta última década - passou da antiglobalização (ou alterglobalização) para a negação da globalização e seus efeitos sobre a economia e o social. Os atuais movimentos latino-americanos, especialmente no Brasil e no Chile, estão operando uma renovação nas lutas sociais da magnitude que os novos movimentos sociais operaram nas décadas de 1960, 1970 e parte de 1980. Eles estão reformulando a pauta das demandas e repolitizando-as de forma nova, na maioria das vezes independente das estruturas partidárias.

Concluímos citando Maria Alice R. de Carvalho ao avaliar as manifestações de junho de 2013:

O principal saldo consistiu na construção de uma "comunidade" não essencializada e indeterminada, isto é, na formação em ato da vontade coletiva, apoiada na intersubjetividade e em pressupostos pragmáticos dos atores. E isso é tão importante porque o fato de indivíduos ordinários terem criado um novo padrão cultural de comunidade extrai a possibilidade de renovação democrática da chave da utopia, dos maciços filosóficos, de seus intérpretes exclusivos e suas lideranças exotéricas. Estamos diante de um movimento que dialoga com a sugestão habermasiana que diz que a solidariedade possível na modernidade tardia é a que se fundamenta racionalmente. Uma solidariedade reflexiva, sinônimo de interesse comum 
racionalmente obtido. Estamos todos juntos (Maria Alice Rezende de Carvalho, 2013).

Concordamos com a autora desde que a utopia não seja reduzida a uma verdade vinda de alguns "intérpretes exclusivos". A utopia - como citamos acima - retorna nas manifestações de rua em junho de 2013 com vigor, em moldes e fundamentos libertários, com foco que prioriza o ser humano e suas necessidades cotidianas, dentre as quais serviços públicos com qualidade, numa sociedade que deve combater as desigualdades de qualquer tipo. A solidariedade reflexiva, criada a partir da intersubjetividades construída nas redes e nos atos de protestos, recoloca o tema do interesse comum. Um tema para um grande debate.

Abstract: This text highlights forms of civil collective actions organized in social movements or social networks that participate in institutionalized programs and social projects in Latin America, with emphasis on the Brazilian case in the last decade. The issues investigated are: Who are the social actors that perform these associative actions? Which public and demands they represent? What impact these demands have generated in society and in government? What answers have they got? At the end some remarks about social events that occurred in June 2013 in Brazil are made in the context of the scenarios presented throughout the text.

Key Words: sociopolitical representation; participation; social movements; civil associations; public councils and forums.

\section{Referências}

ABERS, Rebecca; Von Bulow, Marisa (Orgs). Dossiê: Movimentos sociais e ação coletiva. Revista Brasileira de Ciência Política, n. 3. Brasília, Jan.-Jul. 2010.

Ali, T.; Alves, G.; Davis, M.; Harvey, D.; Sader, E.; Safatle, V.; Peschanski, J. Al; Žıžek, S.; Teles, E.; WAlleRstein, I. Occupy. Movimentos de protestos que tomaram as ruas. São Paulo: Boitempo, 2012.

BORON, Atílio; LECHINI, Gladys (Orgs.). Política y movimientos sociales en un mundo hegemónico. Lecciones desde África, Ásia y América Latina. Buenos Aires: Clacso, 2006.

Carvalho, Maria Alice Rezende de. Bom para pensar. Boletim Cedes. Jul.-Set. 2013.

CASTELLS, Manuel. Redes de indignação e de esperança: movimentos sociais na era global. Rio de Janeiro: Zahar, 2013.

DIANI, Mário; MACADAM Doug (Eds.). Social movements and networks: relational approaches collective actions. Oxford: Oxford University Press, 2003

DI CINTIO, Chloé. Petit traité de désobéissance civile. Paris: ResPublica, 2010.

Di MARCo, Graziela; PALOMIno, Héctor. Reflexiones sobre los movimientos sociales en la Argentina. Buenos Aires: Unansam, 2004. 
DelLA PORTA, Donatella. O movimento por uma nova globalização. São Paulo: Loyola, 2007.

Della PortA, Donatella; TARRow, Sidney. Transnational protest and global activism. London: Roman \& Littlefield Publis., 2005.

DUSSEL, Enrique. A ética da libertação na idade da exclusão. Petrópolis: Vozes, 2002.

Gorn, Maria da Glória. Sociologia dos movimentos sociais. 2. ed. São Paulo: Cortez, 2014a.

Manifestações de junho de 2013 no Brasil e praças dos Indignados no mundo. Petrópolis: Vozes, 2014b.

_. Movimentos sociais e redes de mobilizações civis no Brasil contemporâneo. 6. ed. Petrópolis: Vozes, 2013b.

- Movimentos e lutas sociais na História do Brasil. 7. ed. São Paulo: Loyola. 2013c.

_. Teorias dos movimentos sociais. Paradigmas clássicos e contemporâneos. 10. ed. São Paulo: Loyola, 2012a.

- Novas teorias dos movimentos sociais. 4. ed. São Paulo: Loyola, 2012b.

- Movimentos sociais e educação. 8. ed. São Paulo: Cortez, 2012c.

HABERMAS, Jürgen. Teoría de la acción comunicativa: racionalidad de la acción y racionalización social. v. I. Madrid: Taurus, 1981.

Direito e democracia: entre facticidade e validade. v. II. Rio de Janeiro: Tempo Brasileiro, 2003.

HarVey, David. O enigma do capital e as crises do capitalismo. São Paulo: Boitempo, 2011.

HESSEL, Stéphane. Indignai-vos! 3. ed. Lisboa: Objectiva, 2011.

HONNETH, Axel. Luta por reconhecimento. A gramática moral dos conflitos sociais. São Paulo: Editora 34, 2003.

Johnston, Hank; AlmeidA, Paul. Latin American social movements: globalization, democratization and transnational networks. New York: Rowman \& Littlefield Publishers, 2007.

LATOUR, Bruno. Reassembling the social: an introduction to actor network theory. Oxford: Oxford University Press, 2005. 
LINERA, Alvaro G. Sociologia dos movimentos sociais. São Paulo: Boitempo, 2009.

McDonald, Kevin. Global movements. Action and culture. Oxford: Blackwell, 2006.

Meluccl, Alberto. Challeging codes. Cambridge: Cambridge Press, 1996.

MIRZA, Christian Adel. Movimientos sociales y partidos políticos en América Latina. Buenos Aires: Clacso, 2006.

Morus, Thomas - A Utopia. Porto Alegre: L\&PM, 1997.

Mumford, Lewis. História das utopias. Lisboa: Antigona, 2007.

NeGRI, Antonio; Cocco, Giuseppe. Global: biopoder e luta em uma América Latina globalizada. São Paulo: Record, 2005.

Nobre, Marcos. Choque de democracia. Razões da revolta. São Paulo: Companhia das Letras, 2013.

Nogueira, Marco Aurélio. As ruas e a democracia. Ensaios sobre o Brasil contemporâneo. São Paulo: Contraponto, 2013.

Observatorio Social de América Latina. Movimientos sociales y gobiernos en la región Andina. Resistencias y alternativas en lo político y lo social. Revista Osal, n. 19. Buenos Aires: Clacso, 2006.

Ortelmado, Pablo; Ryoki, Andre. Estamos vencendo. Resistência global no Brasil. São Paulo: Conrad, 2012.

PESCHANSKI, João Alexandre. O transporte público gratuito, uma utopia real. In: HARVEY, David; MARICATO, Ermínia; ŽIŽEK, Slavoj et alii. Cidades rebeldes: passe livre e as manifestações que tomaram as ruas no Brasil. São Paulo: Boitempo, 2013.

QuiJANo, Aníbal. El laberinto de América Latina: ¿hay otras salidas? Revista Osal, v. 5, n. 13. Buenos Aires, Clacso, 2004.

Riot-SarceY, Michèle; Picon, Antoine; Bouchet, Thomas. Dicionário das utopias. São Paulo: Edições \& Textos, 2009.

SADER, Eder. Quando novos personagens entraram em cena. Rio de Janeiro: Paz e Terra, 1988.

SANTOS, Boaventura de S. (Org.). A gramática do tempo. Para uma nova cultura política. São Paulo: Cortez, 2006.

As vozes do mundo. Rio de Janeiro: Civilização Brasileira, 2009. 
SAlıBA, Elias Thomé. As utopias românticas. 3. ed. São Paulo: Estação Liberdade, 2004.

SCherer-WARRen, Ilse. Movimentos sociais e geração de novos direitos em tempos globais: o caso brasileiro. In: GoHn, Maria da Gloria; BRINGEL, Breno M. (Orgs.). Movimentos sociais na era global. Petrópolis: Vozes, 2012.

SeoAne, José; TAddel, Emilio (Orgs.). Resistências mundiais. Petrópolis: Vozes, 2001.

SeOAne, José; TAdDeI, Emilio; Algranati, Clara. Las nuevas configuraciones de los movimientos populares em América Latina. In BORON, Atílio; LeCHINI, Gladys (Orgs.). Política y movimientos sociales em um mundo hegemônico. Lecciones desde Africa, Asia y America Latina. Buenos Aires: Clacso, 2006.

SPIVAK, Gayatri C. Estudios de La subalternidad. In SPIVAK, Gayatri C. et alii. Estudios postcoloniales - Ensayos fundamentales. Madrid: Queimadas Graficas, 2008.

Svampa, Maristella. Cambio de época. Movimientos sociales y poder político. Buenos Aires: Clacso/SigloXXI, 2008.

TAPIA, L. Movimientos sociales, movimientos societales y los no lugares de la política. Cuadernos del Pensamiento Crítico Latinoamericano, n. 11. Buenos Aires: Clacso, 2009.

TARrow, Sidney. Power in movement. Cambridge: Cambridge Press, 1994.

_. New transnational activism. Cambridge: Cambridge Press, 2005.

TILly, charles; TARrow, S. Contentiouys Politics. Boulder: Paradigm Publis, 2007.

TOURAINE, Alain. Un nouveau paradigme. Paris: Fayard, 2005.

_. O mundo das mulheres. Petrópolis: Vozes, 2006.

ŽıžEK, Slavoj. Primeiro como tragédia, depois como farsa. São Paulo: Boitempo, 2011. 